Complete Manuscript Title:

\title{
Preliminary Evidence of a Link between COVID-19 Vaccines and Otologic Symptoms
}

\author{
Short Running Head: \\ COVID-19 Vaccines and Otologic Symptoms \\ Authors: \\ Ramsi A. Woodcock, JD, MSc* \\ Assistant Professor \\ University of Kentucky Rosenberg College of Law \\ Secondary Appointment \\ Department of Management \\ University of Kentucky Gatton College of Business \& Economics \\ Law Building \\ 620 S. Limestone \\ Lexington, KY 40506 \\ United States of America \\ Office Phone: +1-859-257-1253 \\ Cell Phone (preferred): +1-646-385-3592 \\ Email: rwo236@uky.edu \\ Loren J. Bartels MD, FACS ${ }^{* *}$ \\ Director, Tampa Bay Hearing and Balance Center \\ Clinical Professor of Otolaryngology \\ University of South Florida College of Medicine \\ 5 Tampa General Circle 610 \\ Tampa, FL 33606 \\ United States of America \\ Office Phone: +1-813-315-4327 \\ Email: lbartels@tampabayhearing.com \\ Sources of Support/Disclosure of Funding: \\ This study received no outside support or funding. \\ Conflicts of Interest:
}

Ramsi A. Woodcock suffers from otologic symptoms that he believes to have been caused by COVID-19 vaccination. He is Loren J. Bartels' patient.

*Contribution: conceptualization; data curation; formal analysis; investigation; methodology; project administration; resources; software; supervision; validation; visualization; writing — original draft; writing-review \& editing. This author is not a medical doctor. His contributions to this paper are not intended to be, nor should they be taken as, medical advice.

${ }^{* *}$ Contribution: methodology; writing — review \& editing. 


\section{COVID-19 Vaccines and Otologic Symptoms}

ABSTRACT

Hypothesis: This study investigates whether U.S. Centers for Disease Control and Prevention

3 Vaccine Adverse Events Reporting System (VAERS) data suggest an association between

4 vertigo, tinnitus, hearing loss, Bell's palsy and the COVID-19 vaccines administered in the

5 United States.

6 Background: Published case reports suggest a possible association between various otologic

7 symptoms and the COVID-19 vaccines, but the only published analysis of VAERS data, which

8 did not account for underreporting of late-appearing adverse events, found no association

9 between hearing loss and the vaccines.

10 Methods: The incidence in VAERS of vertigo, tinnitus, hearing loss, and Bell's palsy associated

11 with COVID-19 vaccinations administered between December 14, 2020 and June 7, 2021 was

12 compared with published rates for the general population. To account for underreporting of late-

13 appearing adverse events, incidences were calculated using only the initial part of the

14 observation period, during which reported events spike above expected events.

15 Results: The COVID-19 vaccines were associated with statistically significant increases in the

16 incidence of vertigo, tinnitus, hearing loss, and Bell's palsy of 1877, 50, 12, and 14 cases per

17100,000 , respectively. In relation to the mRNA-1273 or BNT162b2 vaccines, the Ad26.COV2.S

18 vaccine was associated with a statistically significant excess incidence of vertigo, tinnitus, and

19 hearing loss of at least 723,57 , and 55 cases per 100,000 , respectively.

20 Conclusion: These results suggest an association between the COVID-19 vaccines and vertigo,

21 tinnitus, hearing loss, and Bell's palsy. They also suggest that, with respect to vertigo, tinnitus,

22 and hearing loss, the association is relatively strong for the Ad26.COV2.S vaccine. 


\section{COVID-19 Vaccines and Otologic Symptoms}

24 Published case reports suggest a possible association between the COVID-19 vaccines and

25 various otologic symptoms, including hearing loss, tinnitus, and vertigo. ${ }^{1-3}$ However, the only

26 preliminary study of otologic symptoms in U.S. Centers for Disease Control and Prevention

27 Vaccine Adverse Event Reporting System (VAERS) data published to date, in which Formeister

28 et al. investigated reports of hearing loss, failed to find an association. ${ }^{4,5}$ This may be because

29 vaccine adverse event reports relate to a single trigger-vaccination — whereas the population

30 incidence rates to which they must be compared relate to multiple triggers. ${ }^{6}$ For example, the

31 population incidence of vertigo includes cases of vertigo due to trauma, viral infection, and genetic

32 disorders, among other things, whereas doctors and patients likely tend to report to VAERS only

33 cases of vertigo that they believe to be triggered by vaccination. As a result, the incidence rate of

34 vertigo in the VAERS reports will be lower than the population incidence rate unless vaccination

35 triggers more vertigo than all other triggers combined.

36 The U.S. Centers for Disease Control and Prevention (CDC) tries to address this problem by

37 encouraging doctors and patients to report all symptoms they encounter after vaccination. ${ }^{7}$ In

38 theory, that should ensure that symptoms due to all triggers, including vaccination, are reported,

39 with the result that, if vaccination triggers additional cases of a particular symptom, then the

40 incidence rate in the VAERS reports will be higher than the population incidence rate and

41 researchers will be able to infer from this difference that there is an association between the

42 symptom and vaccination.

43 Unfortunately, doctors and patients do not heed the CDC. As Figure 1 shows, VAERS reports

44 for all vaccines, COVID or otherwise, decline dramatically as the date of onset of the reported 


\section{COVID-19 Vaccines and Otologic Symptoms}

45 symptom extends beyond the vaccination date. If doctors and patients were to report all symptoms

46 based on all triggers, including post-vaccination triggers, one would expect the line to be

47 approximately flat, unless vaccination is a disproportionate source of all symptoms experienced

48 by the population due to any cause, which is unlikely. In the absence of any test enabling doctors

49 and patients to determine whether a particular symptom is caused by vaccination, doctors and

50 patients rely on proximity of the date of symptom onset to the date of vaccination as a proxy for

51 causation, which explains why, in Figure 1, reports spike for symptoms with onset immediately

52 after vaccination and then fall off almost to zero after a few weeks. ${ }^{8}$ As shown in Figure 3 , VAERS

53 reports for the symptoms considered in this study_vertigo, tinnitus, hearing loss, and Bell's

54 palsy - all exhibit a similar initial spike in reported symptoms with onset immediately after

55 vaccination, followed by a precipitous decline in reported symptoms as the date of onset moves

56 farther away from the date of vaccination.

57 One way around the failure of doctors and patients fully to report symptoms due to non-

58 vaccine triggers would be to use published reporting sensitivity rates to inflate the raw number of

59 VAERS reports. Unfortunately, existing studies of VAERS reporting sensitivity, such as that of

60 Miller et al., are based on VAERS reports that have been selected for their temporal proximity to

61 vaccination - the same filter that doctors and patients place on their own reporting - and hence

62 are unlikely fully to capture underreporting of symptoms associated with non-vaccine triggers. ${ }^{9}$

63 Sensitivity rates extrapolated from a comparison with clinical trial adverse event reports suffer

64 from a similar limitation, because clinical trials solicit reports only within a few days of 65 vaccination.

66 Fortunately, there is another way around the underreporting of non-vaccine-triggered events. 


\section{COVID-19 Vaccines and Otologic Symptoms}

67 If the number of cases reported during the peak reporting period immediately after vaccination-

68 the "spike period"- exceeds the number of cases expected during that period based on the

69 population incidence rate of the symptom, then it follows that the vaccine is a trigger of the

70 symptom, even if reported cases fall below expected cases for the rest of the observation period,

71 and even if the incidence rate implied by the reports, if calculated over the entire observation

72 period, is below the population incidence rate. For the only way in which reported cases can

73 exceed expected cases during any part of an observation period, despite underreporting of cases

74 due to non-vaccine triggers, is if vaccine-triggered cases of the symptom are numerous enough

75 over that period to make up the difference. But the existence of any number of vaccine-triggered

76 cases, if statistically significant in magnitude, is sufficient to establish an association between the

77 vaccine and the symptom.

78 Consider a numerical illustration. Suppose that vaccination triggers one hundred excess cases

79 of vertigo in the first day after vaccination and none on the second day, and that all other triggers

80 cause an additional hundred cases every day, but that doctors and patients, despite reporting all

81 symptoms on the first day regardless of trigger, report none on the second day, because they

82 assume that none of the day-two symptoms are triggered by the vaccine. If $365,000,000$

83 vaccinations are observed, then for a 2-day observation period, the incidence of vertigo is 10 (per

84100,000 person-years, as with all incidence rates discussed in the present study), but the population

85 incidence (which is based on the number of cases caused by all other triggers) is 15, suggesting,

86 falsely, that there is no association between vaccination and the symptom. If, however, one

87 considers only the first day, during which total reported cases of 200 spike above expected cases

88 of 100 , then the incidence is 20 , which exceeds the population incidence of 15 and therefore 


\section{COVID-19 Vaccines and Otologic Symptoms}

89 correctly indicates the existence of an association.

90 An additional consideration complicates analysis of spike periods: reports may not be

91 accurate. As a result, the presence of a spike in raw report numbers for a particular symptom is

92 not sufficient to suggest the existence of an association between the vaccine and the symptom.

93 The spike must be discounted, either through examination of individual reports or by a rate of

94 accuracy derived from analysis of past reports. Even if discounting eliminates the spike, however,

95 the analysis does not end, because the studies, such as that of Miller et al., that provide sensitivity

96 rates for reporting of adverse events with onset close to the date of vaccination are likely to capture

97 underreporting during spike periods even if they do not capture underreporting of cases

98 thereafter. ${ }^{9}$ The same is true for sensitivity rates extrapolated from a comparison with clinical trial

99 reports. Published sensitivity rates and those extrapolated from clinical trials can therefore be used

100 to offset the accuracy discount with a multiplier that accounts for underreporting during the spike.

103 (Moderna's mRNA-1273, Pfizer-BioNTech's BNT162b2, and Johnson \& Johnson's

104 Ad26.COV2.S) and otologic symptoms, analysis of spikes in reports to VAERS of vertigo,

105 tinnitus, hearing loss, and Bell's palsy over expected levels were carried out. To avoid bias

106 associated with the ongoing arrival of new reports regarding the COVID-19 vaccines, the analysis

107 was limited to vaccines administered between December 14, 2020 and June 7, 2021, to symptoms

108 with an onset within 30 days of vaccination, and to reports made within 60 days of vaccination.

109 The MedDRA-coded symptom fields in the VAERS database were searched for "vertigo,"

110 "tinnitus," "hearing loss," "bell's palsy," and synonyms, and the results filtered for the 


\section{COVID-19 Vaccines and Otologic Symptoms}

111 “COVID19" vaccine type to create datasets for each symptom. Table 1 and Figure 2 provide more

112 information on the search terms, datasets, and study parameters.

113 Formeister et al. manually reviewed each VAERS adverse event report in their study sample

114 for accuracy. For the present study of multiple symptoms relating to nearly seven months of

115 vaccinations, as opposed to the study of a single symptom over 2.5 months carried out by

116 Formeister et al., manual verification could not be undertaken. Instead, a best-guess accuracy rate

117 was identified by running the same search of the VAERS data for hearing loss reported by

118 Formeister et al. and using the resulting case count of 475 to extrapolate an accuracy rate of $8 \%$

119 from Formeister et al.'s conclusion that only 40 reported cases in their VAERS data were accurate.

120 This appears to be a very low accuracy rate. By contrast, an accuracy rate of $57 \%$ is implied by

121 the work of Su et al. on anaphylaxis reports to VAERS in relation to a number of non-COVID-19

122 vaccines. $^{10}$

123 A reporting sensitivity rate of $30 \%$, corresponding to a multiplier of 3.3, was used for tinnitus,

124 hearing loss, and Bell's palsy. This rate was obtained by averaging the rates reported by Miller et

125 al. for reports of anaphylaxis and Guillain-Barré syndrome associated with non-COVID-19

126 vaccinations. ${ }^{9}$ It is somewhat lower than the $50 \%$ sensitivity rate that appears to have been

127 arbitrarily chosen for sensitivity testing of hearing loss reports by Formeister et al.

128 A much lower sensitivity rate- $0.6 \%$, corresponding to a multiplier of 166.9 — was used for

129 vertigo, because, as Neuhauser has pointed out, vertigo is common in the general population,

130 affecting between $20 \%$ and $30 \%$ of adults. ${ }^{11}$ Doctors and patients may therefore be less likely to

131 report vertigo in connection with the COVID-19 vaccines than they are to report tinnitus, hearing

132 loss, or Bell's palsy, each of which is rare in comparison. ${ }^{11}$ To identify an appropriate reporting 


\section{COVID-19 Vaccines and Otologic Symptoms}

133 sensitivity rate for vertigo, the incidence of other common symptoms — pain, erythema, swelling,

134 fever, headache, fatigue, myalgia, and nausea or vomiting-reported in the COVID-19 vaccines'

135 Phase III clinical trials was compared with the incidence of the same symptoms in the VAERS

136 reports and the largest result - that for fever - was used to obtain the $0.6 \%$ reporting sensitivity

137 rate. ${ }^{12-14}$ A comparison with clinical trial reports was considered probative of the true reporting

138 sensitivity rate during the spike period because clinical trial administrators solicit reports from

139 trial subjects within seven days of vaccination. ${ }^{12-14}$

140 Spike periods were determined after application of the $8 \%$ accuracy discount and the

141 applicable underreporting multiplier to the VAERS report counts for each symptom. As shown in

142 Figure 3 and discussed more fully in the Results section, the spike period was two days each for

143 vertigo, tinnitus, and Bell's palsy, and one day for hearing loss. The statistical significance of the

144 incidence rate of each symptom over its spike period, in relation to the published population

145 incidence rate for the symptom, was determined using the normal approximation to the binomial

146 distribution for one-sample inference with two tails. ${ }^{15-18}$

147 The proportional reporting ratio (PRR), ${ }^{19}$ which compares the incidence rate of symptoms in

148 reports related to the vaccine at issue (here, the COVID-19 vaccines) to the rate of all other

149 symptoms in all other VAERS reports, ${ }^{20}$ was also calculated for all four symptoms. The PRR has

150 two helpful features. First, it compares VAERS data with other VAERS data, so the problem of

151 comparing single-trigger VAERS incidence rates to multiple-trigger population incidence rates is

152 avoided. Second, the PRR provides a useful check on the appropriateness of the accuracy and

153 reporting sensitivity rates used in the present study, because, if accuracy and reporting sensitivity

154 rates are constant across all vaccines, then these rates cancel out of the PRR, making the PRR 


\section{COVID-19 Vaccines and Otologic Symptoms}

155 invariant in reporting accuracy and sensitivity assumptions. The statistical significance of the

156 PRRs, in relation to the null hypothesis of one (i.e. that there is no difference between the

157 incidence of the symptom in COVID-19 vaccine reports and the incidence of all other symptoms

158 in all other vaccine reports) was determined using the chi-squared test with one degree of freedom.

159 Finally, to investigate the relative association of different COVID-19 vaccines with vertigo,

160 tinnitus, hearing loss, and Bell's palsy, VAERS spike-period case counts, discounted as above,

161 were categorized by vaccine manufacturer, incidence rates for each were calculated using CDC

162 data on total administered vaccine doses per manufacturer, and, for each symptom, the normal

163 approximation to the binomial distribution for two-sample inference was applied with two tails.

164 For all three tests, p-values below 0.05 were considered significant.

165 University of Kentucky determined that this study is exempt from institutional review board

166 approval because the study uses deidentified data publicly available on the CDC website.

Figure 3 shows the distribution of cases, after adjustment for accuracy and underreporting, in

169 terms of time to symptom onset, including the spike period for each symptom. The incidence rate

170 of vertigo in the VAERS reports over vertigo's two-day spike period was 3,277 (per 100,000

171 person-years, as for all incidence rates reported here), significantly in excess of the population

172 incidence of vertigo of 1,400 reported by Neuhauser et al. $(\mathrm{p}<0.00001) .{ }^{17}$ The incidence rate of

173 tinnitus in the VAERS reports over tinnitus's two-day spike period was 104, significantly in

174 excess of the population incidence of tinnitus of 54 reported by Martinez et al. $(\mathrm{p}<0.00001){ }^{16}$

175 The incidence rate of hearing loss in the VAERS reports over hearing loss's one-day spike period

176 was 39, significantly in excess of the population incidence of hearing loss of 27 reported by 


\section{COVID-19 Vaccines and Otologic Symptoms}

177 Alexander et al. $(\mathrm{p}<0.00001) .{ }^{18}$ The incidence rate of Bell's palsy in the VAERS reports over

178 Bell's palsy's two-day spike period was 37, significantly in excess of 23 , which is the average of

179 the population incidence rates for Bell's palsy referenced by Ozonoff et al. $(\mathrm{p}<0.00001) .{ }^{15}$ As

180 Table 2, which reports these results, shows, incidence rates calculated using the three-week

181 observation period employed by Formeister et al., rather than the spike periods, were, by contrast,

182 all lower than their respective population incidence rates, by 846 for vertigo, 36 for tinnitus, 22

183 for hearing loss, and 14 for Bell's palsy. Incidence rates in the VAERS reports break even with

184 population incidence rates at approximately a one-week observation period.

185 The results for vertigo and tinnitus were robust to lower underreporting multipliers. As Table

1862 also reports, a statistically significant excess incidence of tinnitus remained after reduction of

187 the underreporting multiplier from 3.3 to the value of 2 used by Formeister et al., and a statistically

188 significant excess incidence of vertigo remained after the underreporting multiplier was scaled

189 down in the same proportion (i.e., by the ratio of 2 to 3.3).

190 The PRRs, which require no assumption regarding the rate of accuracy or the rate of reporting

191 sensitivity, were, for vertigo, tinnitus, hearing loss, and Bell's palsy, 4.76, 5.41, 2.63, and 1.46,

192 respectively, as shown in Table 3. Those for vertigo and tinnitus exceeded the null hypothesis of

193 one to a statistically significant degree ( $\mathrm{p}<0.001$ for vertigo and $\mathrm{p}<0.0001$ for tinnitus). This

194 result was consistent with the robustness of the spike period results for vertigo and tinnitus.

195 These results were clinically significant. As Table 2 shows, over the course of the two-day

196 spike period after vaccination, 30,761 of the 171 million people who received at least one dose of

197 vaccine in the United States during the study period (about 1 per 5,569 persons receiving at least

198 one dose) are estimated to have had vertigo. That was 17,619 more cases than the 13,142 cases 
medRxiv preprint doi: https://doi.org/10.1101/2022.02.23.22271144; this version posted February 24, 2022. The copyright holder for this preprint (which was not certified by peer review) is the author/funder, who has granted medRxiv a license to display the preprint in perpetuity.

It is made available under a CC-BY-NC-ND 4.0 International license .

\section{COVID-19 Vaccines and Otologic Symptoms}

199 that were expected over that period based on the population incidence of vertigo (an excess rate

200 of 1 per 9,723 persons receiving at least one dose). For tinnitus, the excess of reported cases over

201 expected cases over the two-day tinnitus spike period was 466 (an excess rate of 1 per 367,579

202 persons receiving at least one dose). For hearing loss, it was 58 excess cases over the one-day

203 hearing loss spike period (about 1 per 2.94 million persons receiving at least one dose), and for

204 Bell's palsy it was 130 excess cases over the two-day Bell's palsy spike period (about 1 extra

205 Bell's palsy case per 1.32 million persons receiving at least one dose).

206 Table 4 sets forth the results regarding the relative associations of the three vaccines

207 administered in the United States. The incidence of vertigo associated with the Ad26.COV2.S

208 vaccine in the VAERS reports was 4,258, in excess of the incidence of 3,535 associated with the

209 mRNA-1273 vaccine and the incidence of 2,947 associated with the BNT162b2 vaccine. The

210 excess in the incidence of vertigo associated with the Ad26.COV2.S vaccine in relation to both

211 the mRNA-1273 vaccine and the BNT162b2 vaccine was statistically significant $(\mathrm{p}<0.00001)$,

212 as was the excess in the incidence of vertigo associated with the mRNA-1273 vaccine in relation

213 to the BNT162b2 vaccine $(\mathrm{p}<0.00001)$. The incidence of tinnitus associated with the

214 Ad26.COV2.S vaccine in the VAERS reports was 157, in excess of the incidence of 100 associated

215 with both the mRNA-1273 and BNT162b2 vaccines to a statistically significant degree $(\mathrm{p}<0.001$

216 and $\mathrm{p}<0.0001$, respectively). The incidence of hearing loss associated with the Ad26.COV2.S

217 vaccine in the VAERS reports was 93, in excess of the incidences associated with the mRNA-

2181273 and BNT162b2 vaccines of 33 and 37, respectively, to a statistically significant degree (p <

2190.00001 and $\mathrm{p}<0.0001$, respectively). The incidence of Bell's palsy associated with the

220 BNT162b2 and mRNA-1273 vaccines in the VAERS reports was 37 for both, which exceeded the 
medRxiv preprint doi: https://doi.org/10.1101/2022.02.23.22271144; this version posted February 24, 2022. The copyright holder for this preprint (which was not certified by peer review) is the author/funder, who has granted medRxiv a license to display the preprint in perpetuity.

It is made available under a CC-BY-NC-ND 4.0 International license.

\section{COVID-19 Vaccines and Otologic Symptoms}

221 incidence of 36 associated with the Ad26.COV2.S vaccine, but not to a statistically significant

222 degree.

223 These results were also clinically significant. The comparatively higher vertigo incidence rate

224 of the Ad26.COV2.S vaccine implies that, had the 171 million people who received at least one

225 vaccine dose over the study period all received the Ad26.COV2.S vaccine, rather than one of the

226 assortment of Ad26.COV2.S, BNT162b2, and mRNA-1273 vaccines that was actually

227 administered, there would have been 39,970 cases of vertigo over the two-day spike period, 9,209

228 more than the 30,761 cases estimated to have actually occurred (an excess rate of about 1 per

22918,602 persons receiving at least one dose). Similarly, the vertigo incidence rate of the mRNA-

2301273 vaccine, which was elevated relative to the vertigo incidence rate of the BNT162b2 vaccine,

231 implies that, had mRNA-1273 alone been administered, there would have been 33,183 cases of

232 vertigo over the two-day spike period, 2,422 more than the 30,761 cases estimated to have actually

233 occurred (an excess rate of about 1 per 70,733 persons receiving at least one dose). The

234 comparatively higher tinnitus incidence rate of the Ad26.COV2.S vaccine implies that, had

235 Ad26.COV2.S alone been administered, there would have been 1,471 cases of tinnitus over the

236 two-day spike period, 498 more than the 973 cases estimated to have actually occurred (an excess

237 rate of 1 per 344,028 persons receiving at least one dose). Finally, the comparatively higher

238 hearing loss incidence rate of the Ad26.COV2.S vaccine implies that, had Ad26.COV2.S alone

239 been administered, there would have been 435 cases of hearing loss over the one-day spike period,

240250 more than the 185 cases estimated to have actually occurred (an excess rate of 1 per 684,947

241 persons receiving at least one dose). 


\section{COVID-19 Vaccines and Otologic Symptoms}

244 and otologic symptoms, particularly vertigo and tinnitus, during the one-to-two-day immediate

245 post-vaccination periods over which reported cases for these symptoms spike above expected

246 cases. The results contrast with results obtained by including cases with later onset in the

247 observation period, such as those published by Formeister et al. The results also suggest that the

248 Ad26.COV2.S vaccine is more likely to trigger vertigo, tinnitus, or hearing loss than are the

249 mRNA-1273 or BNT162b2 vaccines. The number of excess cases of vertigo, tinnitus, hearing loss,

250 and Bell's palsy associated with the vaccines is quite small relative to the total number of people

251 who have received a dose of the vaccines, particularly in the case of tinnitus, hearing loss, and

252 Bell's palsy, but still clinically significant. The existence of an association over the one-to-two-

253 day spike periods does not exclude the existence of an association between the vaccines and

254 symptoms with later onset. Underreporting to VAERS prevents verification of such an association,

255 however.

256 More investigation is required to confirm these associations, because the true accuracy and

257 underreporting sensitivity rates are unknown. One reason for which the $30 \%$ sensitivity rate

258 applied for tinnitus, hearing loss, and Bell's palsy might be incorrect is that media attention paid

259 to the COVID-19 vaccines may have pushed their reporting sensitivity rates above those of the

260 vaccines considered by Miller et al., upon which the $30 \%$ rate is based. ${ }^{9,21}$ More investigation is

261 also required to determine the extent of recovery from the symptoms considered in the present

262 study, either to tolerability or to complete resolution, especially as there are reports of

263 improvement for some symptoms. ${ }^{2,3}$ 
265 This study created a novel way to compare the incidence of post-vaccine symptoms to

266 published population incidence rates by using only cases with onset in the immediate one-to-two-

267 day post-vaccination periods during which reported cases spike above expected cases to calculate

268 incidence rates. In looking at VAERS reports of vertigo, tinnitus, hearing loss, and Bell's palsy in

269 recipients of COVID-19 vaccines, statistical evidence of an association of the vaccines with an

270 excess of these cases appears at rates ranging from about 1 excess case per 5,500 vaccinated

271 persons to about 1 excess case per 2.94 million vaccinated persons. Variations of this methodology

272 might be helpful in investigating the risks of other vaccines. 
medRxiv preprint doi: https://doi.org/10.1101/2022.02.23.22271144; this version posted February 24, 2022. The copyright holder for this preprint (which was not certified by peer review) is the author/funder, who has granted medRxiv a license to display the preprint in perpetuity. It is made available under a CC-BY-NC-ND 4.0 International license .

\section{COVID-19 Vaccines and Otologic Symptoms}

274 1. Wichova H, Miller ME, Derebery MJ. Otologic Manifestations After COVID-19 Vaccination:

275 The House Ear Clinic Experience. Otol Neurotol. Published online July 9, 2021. doi:10.1097/MAO.0000000000003275

2. Tseng P-T, Chen T-Y, Sun Y-S, Chen Y-W, Chen J-J. The reversible tinnitus and cochleopathy followed first-dose AstraZeneca COVID-19 vaccination. QJM. Published online July 23, 2021. doi:10.1093/qjmed/hcab210

3. Parrino D, Frosolini A, Gallo C, Siati RDD, Spinato G, Filippis C de. Tinnitus following COVID-19 vaccination: report of three cases. Int J Audiol. Published online June 13, 2021:1-

$$
\text { 4. doi:10.1080/14992027.2021.1931969 }
$$

4. Formeister EJ, Chien W, Agrawal Y, Carey JP, Stewart CM, Sun DQ. Preliminary Analysis of Association Between COVID-19 Vaccination and Sudden Hearing Loss Using US Centers for Disease Control and Prevention Vaccine Adverse Events Reporting System Data. JAMA Otolaryngol Head Neck Surg. 07 01, 2021;147(7):674-676. doi:10.1001/jamaoto.2021.0869

5. Data. VAERS. Accessed October 1, 2021. https://vaers.hhs.gov/data.html

6. Viele K, Berry S, Neuenschwander B, et al. Use of historical control data for assessing treatment effects in clinical trials. Pharmaceutical Statistics. 2014;13(1):41-54. doi:https://doi.org/10.1002/pst.1589

7. FAQs. VAERS. Accessed September 14, 2021. https://vaers.hhs.gov/faq.html 
medRxiv preprint doi: https://doi.org/10.1101/2022.02.23.22271144; this version posted February 24, 2022. The copyright holder for this preprint (which was not certified by peer review) is the author/funder, who has granted medRxiv a license to display the preprint in perpetuity. It is made available under a CC-BY-NC-ND 4.0 International license .

\section{COVID-19 Vaccines and Otologic Symptoms}

295

296

297

298

299

300

301

302

303

304

305

306

307

308

309

310

9. Miller ER, McNeil MM, Moro PL, Duffy J, Su JR. The reporting sensitivity of the Vaccine Adverse Event Reporting System (VAERS) for anaphylaxis and for Guillain-Barré syndrome. Vaccine. 11 03, 2020;38(47):7458-7463. doi:10.1016/j.vaccine.2020.09.072

10. Su JR, Moro PL, Ng CS, Lewis PW, Said MA, Cano MV. Anaphylaxis after vaccination reported to the Vaccine Adverse Event Reporting System, 1990-2016. Journal of Allergy and Clinical Immunology. 2019;143(4):1465-1473. doi:10.1016/j.jaci.2018.12.1003

11. Neuhauser HK. Epidemiology of vertigo. Current Opinion in Neurology. 2007;20(1):40-46. doi:10.1097/WCO.0b013e328013f432

12. FDA Emergency Use Authorization (EUA) for an Unapproved Product Review Memorandum (Moderna COVID-19 Vaccine/mRNA-1273). Published December 18, 2020. https://www.fda.gov/media/144673/download

13. FDA Emergency Use Authorization (EUA) for an Unapproved Product Review Memorandum (Pfizer-BioNTech COVID-19 Vaccine/BNT162b2). Published December 11, 2020. https://www.fda.gov/media/144416/download

14. FDA Emergency Use Authorization (EUA) for an Unapproved Product Review Memorandum (Janssen COVID-19 Vaccine/Ad26.COV2.S). Published February 27, 2021. https://www.fda.gov/media/146338/download

15. Ozonoff A, Nanishi E, Levy O. Bell's palsy and SARS-CoV-2 vaccines. The Lancet Infectious Diseases. 2021;21(4):450-452. doi:10.1016/S1473-3099(21)00076-1

16. Martinez C, Wallenhorst C, McFerran D, Hall DA. Incidence Rates of Clinically Significant Tinnitus: 10-Year Trend From a Cohort Study in England. Ear and Hearing. 2015;36(3):e69. doi:10.1097/AUD.0000000000000121 
317 17. Neuhauser HK, Radtke A, von Brevern M, Lezius F, Feldmann M, Lempert T. Burden of

318 Dizziness and Vertigo in the Community. Arch Intern Med. 2008;168(19):2118.

319 doi:10.1001/archinte.168.19.2118

320 18. Alexander TH, Harris JP. Incidence of sudden sensorineural hearing loss. Otol Neurotol.

321 2013;34(9):1586-1589. doi:10.1097/MAO.0000000000000222

322 19. Evans SJ, Waller PC, Davis S. Use of proportional reporting ratios (PRRs) for signal 323 generation from spontaneous adverse drug reaction reports. Pharmacoepidemiol Drug Saf. 324 2001;10(6):483-486. doi:10.1002/pds.677

325 20. Almenoff JS, Pattishall EN, Gibbs TG, DuMouchel W, Evans SJW, Yuen N. Novel Statistical 326 Tools for Monitoring the Safety of Marketed Drugs. Clinical Pharmacology \& Therapeutics. 2007;82(2):157-166. doi:https://doi.org/10.1038/sj.clpt.6100258

328 21. Eberth JM, Kline KN, Moskowitz DA, Montealegre JR, Scheurer ME. The Role of Media and 329 the Internet on Vaccine Adverse Event Reporting: A Case Study of Human Papillomavirus 330 Vaccination. Journal of Adolescent Health. 2014;54(3):289-295. 331 doi:10.1016/j.jadohealth.2013.09.005 


\section{COVID-19 Vaccines and Otologic Symptoms}

VII. FIGURE LEGENDS

335 for All Vaccines, COVID-19 and Non-COVID-19, Administered between December 14, 2020 and

336 June 7, 2021.

337 Figure 2: Triangle Venn Diagram Showing the Intersection of the Sets of Reports of Vertigo

338 (V), Tinnitus (T), and Hearing Loss (H) in VAERS data.

339 Figure 3: Spike Periods for Otologic Symptoms: Reports to VAERS of (a) Vertigo, (b)

340 Tinnitus, (c) Hearing Loss, and (d) Bell's Palsy in Relation to the COVID-19 Vaccines for Doses

341 Administered between December 14, 2020 and June 7, 2021, Showing Spike Periods During

342 Which Reported Cases Exceed Expected Cases. The solid line shows the number of cases reported

343 and the horizontal dashed line shows the expected number of cases based on the population

344 incidence rate. The vertical dotted line shows the number of days after dose administration at

345 which the spike of reported cases above expected cases ends. The vertical axis is labeled in report

346 numbers and the horizontal access is labeled in the number of days between administration of the

347 dose and symptom onset. An accuracy discount rate of $8 \%$ has been applied to all case counts, an

348 underreporting multiplier of 3.3 has been applied to the tinnitus, hearing loss, and Bell's palsy case

349 counts, and an underreporting multiplier of 166.9 has been applied to the vertigo case counts. 
medRxiv preprint doi: https://doi.org/10.1101/2022.02.23.22271144; this version posted February 24, 2022. The copyright holder for this preprint (which was not certified by peer review) is the author/funder, who has granted medRxiv a license to display the preprint in perpetuity.

It is made available under a CC-BY-NC-ND 4.0 International license.

Tables for "Preliminary Evidence of a Link between COVID-19 Vaccines and Otologic Symptoms"

\begin{tabular}{|c|c|c|}
\hline \multicolumn{3}{|c|}{ Table 1: Overview of the Data Used in the Study. } \\
\hline \multirow{3}{*}{ Study parameters } & $\begin{array}{c}\text { Period over which vaccinations included in the } \\
\text { study were administered }\end{array}$ & $\begin{array}{c}\text { December 14, } 2020 \text { to } \\
\text { June } 7,2021\end{array}$ \\
\hline & Days after vaccination observed & 30 \\
\hline & $\begin{array}{c}\text { Days after vaccination during which adverse } \\
\text { event reports were collected }\end{array}$ & 60 \\
\hline \multirow{4}{*}{$\begin{array}{c}\text { Vertigo }{ }^{1} \text { cases } \\
\text { reported to VAERS } \\
\text { (search term: "vertigo") }\end{array}$} & Total cases & 3,993 \\
\hline & mRNA-1273 & 1,713 \\
\hline & BNT162b2 & 1,950 \\
\hline & Ad26.COV2.S & 323 \\
\hline \multirow{4}{*}{$\begin{array}{c}\text { Tinnitus }^{2} \text { cases } \\
\text { reported to VAERS } \\
\text { (search terms: "tinnitus"; "hypoacusis") }\end{array}$} & Total cases & 6,562 \\
\hline & mRNA-1273 & 2,615 \\
\hline & BNT162b2 & 3,366 \\
\hline & Ad26.COV2.S & 573 \\
\hline \multirow{4}{*}{$\begin{array}{c}\text { Hearing loss }{ }^{3} \text { cases reported to VAERS } \\
\text { (search terms: "hearing loss"; } \\
\text { "deafness"; "hypoacusis") }\end{array}$} & Total cases & 1,962 \\
\hline & mRNA-1273 & 750 \\
\hline & BNT162b2 & 1,036 \\
\hline & Ad26.COV2.S & 170 \\
\hline \multirow{4}{*}{$\begin{array}{c}\text { Bell's palsy }{ }^{4} \text { cases reported to VAERS } \\
\text { (search terms: "bell's palsy"; "facial } \\
\text { palsy"; "facial paralysis") }\end{array}$} & Total cases & 3,541 \\
\hline & mRNA-1273 & 1,463 \\
\hline & BNT162b2 & 1,824 \\
\hline & Ad26.COV2.S & 248 \\
\hline \multirow{4}{*}{$\begin{array}{c}\text { Overall vaccinated population (at least } \\
\text { one dose })^{5}\end{array}$} & Total & $171,310,738$ \\
\hline & mRNA-1273 & $69,355,687$ \\
\hline & BNT162b2 & $90,933,285$ \\
\hline & Ad26.COV2.S & $11,021,766$ \\
\hline
\end{tabular}

${ }^{1}$ Cases by manufacturer do not sum to total cases because the vaccine manufacturer was not identified in seven cases.

${ }^{2}$ Cases by manufacturer do not sum to total cases because the vaccine manufacturer was not identified in eight cases.

${ }^{3}$ Cases by manufacturer do not sum to total cases because the vaccine manufacturer was not identified in six cases.

${ }^{4}$ Cases by manufacturer do not sum to total cases because the vaccine manufacturer was not identified in six cases.

${ }^{5}$ The manufacturer figures have been scaled to equal the total number of first-doses reported by the CDC to have been administered. It is not clear why the manufacturer figures reported by the CDC do not sum to the total without scaling. 
medRxiv preprint doi: https://doi.org/10.1101/2022.02.23.22271144; this version posted February 24, 2022. The copyright holder for this preprint (which was not certified by peer review) is the author/funder, who has granted medRxiv a license to display the preprint in perpetuity.

It is made available under a CC-BY-NC-ND 4.0 International license .

Tables for "Preliminary Evidence of a Link between COVID-19 Vaccines and Otologic Symptoms"

\begin{tabular}{|c|c|c|c|}
\hline \multicolumn{4}{|c|}{$\begin{array}{l}\text { Table 2: Comparing Spike Period Incidence Rates to General Population Incidence Rates. } \\
\text { All incidence rates are annual per 100,000 persons. }\end{array}$} \\
\hline Symptom & $\begin{array}{l}\text { Cases During Spike Period / } \\
\text { Expected Cases for Spike } \\
\text { Period / Spike Period (Days) }\end{array}$ & $\begin{array}{c}\text { Incidence over Spike Period (95\% CI) } \\
\text { / General Population Incidence / } \\
\text { Incidence over 21-Day Observation } \\
\text { Period }\end{array}$ & $\begin{array}{l}\text { z-statistic / p-value (two- } \\
\text { tailed) / significant at the } \\
95 \% \text { confidence level? }\end{array}$ \\
\hline \multicolumn{4}{|c|}{ Accuracy: $8 \%$; Reporting Sensitivity/Multiplier: 30\%/3.3 (vertigo: 0.6\%/166.9); Overall: $28 \%$ (vertigo: 1,405\%) } \\
\hline Vertigo & $30,760.64 / 13,141.65 / 2$ & $\begin{array}{c}3,276.98(3,240.96,3,313.00) / 1,400 / \\
554.47\end{array}$ & $154.78 /<0.00001 /$ yes \\
\hline Tinnitus & $972.94 / 506.89 / 2$ & $103.65(97.14,110.16) / 54 / 18.06$ & $20.71 /<0.00001 /$ yes \\
\hline $\begin{array}{l}\text { Hearing } \\
\text { Loss }\end{array}$ & $185.07 / 126.72 / 1$ & $39.43(33.75,45.11) / 27 / 5.34$ & $5.18 /<0.00001 /$ yes \\
\hline $\begin{array}{l}\text { Bell's } \\
\text { Palsy }\end{array}$ & $346.06 / 215.90 / 2$ & $36.87(32.98,40.75) / 23 / 9.27$ & $8.86 /<0.00001 /$ yes \\
\hline \multicolumn{4}{|c|}{ Accuracy: $8 \%$; Reporting Sensitivity/Multiplier: 50\%/2 (vertigo: 1\%/100); Overall: 17\% (vertigo: $845 \%$ ) } \\
\hline Vertigo & $18,503.71 / 13,141.65 / 2$ & $\begin{array}{c}1,971.23(1,943.11,1,999.35) / 1,400 / \\
333.53\end{array}$ & $47.11 /<0.00001 /$ yes \\
\hline Tinnitus & $338.53 / 253.45 / 1$ & $72.13(64.45,79.81) / 54 / 10.87$ & $5.35 /<0.00001 /$ yes \\
\hline $\begin{array}{l}\text { Bell's } \\
\text { Palsy }\end{array}$ & $122.44 / 107.95 / 1$ & $26.09(21.47,30.71) / 23 / 5.58$ & $1.40 / 0.16 /$ no \\
\hline $\begin{array}{l}\text { Hearing } \\
\text { Loss }\end{array}$ & \multicolumn{3}{|c|}{$\begin{array}{c}\text { No spike period; reported cases never exceed expected cases, suggesting the absence of a positive } \\
\text { association between hearing loss and the COVID-19 vaccines. Incidence over a } 21 \text {-day observation } \\
\text { period is } 3.21 \text { per } 100,000 \text { person-years. }\end{array}$} \\
\hline
\end{tabular}


medRxiv preprint doi: https://doi.org/10.1101/2022.02.23.22271144; this version posted February 24, 2022. The copyright holder for this preprint (which was not certified by peer review) is the author/funder, who has granted medRxiv a license to display the preprint in perpetuity.

It is made available under a CC-BY-NC-ND 4.0 International license .

Tables for "Preliminary Evidence of a Link between COVID-19 Vaccines and Otologic Symptoms"

\begin{tabular}{|c|c|c|c|c|c|}
\hline \multicolumn{6}{|c|}{ Table 3: Proportional Reporting Ratios for Vertigo, Tinnitus, Hearing Loss, and Bell's Palsy. } \\
\hline Variable & $\begin{array}{c}\text { (a) Cases } \\
\text { after a } \\
\text { COVID-19 } \\
\text { vaccine dose }\end{array}$ & $\begin{array}{l}\text { (b) Reports of all } \\
\text { other adverse } \\
\text { events after a } \\
\text { COVID-19 } \\
\text { vaccine dose }\end{array}$ & $\begin{array}{l}\text { (c) Cases after } \\
\text { all other non- } \\
\text { COVID-19 } \\
\text { vaccine doses }\end{array}$ & $\begin{array}{l}\text { (d) Reports of all } \\
\text { other adverse events } \\
\text { after all other non- } \\
\text { COVID-19 vaccine } \\
\text { doses }\end{array}$ & $\begin{array}{c}\text { PRR }\left(\frac{\overline{a+b}}{\frac{c}{c+d}}\right) / \chi^{2} \\
\text { statistic }(1 \mathrm{df}) / \mathrm{p}- \\
\text { value / significant at } \\
\text { the } 95 \% \text { confidence } \\
\text { level? }\end{array}$ \\
\hline Vertigo & 3,993 & 458,837 & 9 & 4,955 & $\begin{array}{c}4.76 / 14.13 /<0.001 / \\
\text { yes }\end{array}$ \\
\hline Tinnitus & 6,562 & 456,268 & 13 & 4,951 & $\begin{array}{c}5.41 / 19.48 /<0.0001 \\
/ \text { yes }\end{array}$ \\
\hline $\begin{array}{l}\text { Hearing } \\
\text { Loss }\end{array}$ & 1,962 & 460,868 & 8 & 4,956 & $\begin{array}{c}2.63 / 2.66 / 0.103 / \\
\text { no }\end{array}$ \\
\hline $\begin{array}{l}\text { Bell's } \\
\text { Palsy }\end{array}$ & 3,541 & 459,289 & 26 & 4,938 & $1.46 / 0.21 / 0.65 /$ no \\
\hline
\end{tabular}


medRxiv preprint doi: https://doi.org/10.1101/2022.02.23.22271144; this version posted February 24, 2022. The copyright holder for this preprint (which was not certified by peer review) is the author/funder, who has granted medRxiv a license to display the preprint in perpetuity.

It is made available under a CC-BY-NC-ND 4.0 International license .

Tables for "Preliminary Evidence of a Link between COVID-19 Vaccines and Otologic Symptoms"

Table 4: Relative Incidence of Vertigo, Tinnitus, Hearing Loss, and Bell's Palsy Associated with the mRNA-1273, BNT162b2, and Ad26.COV2.S COVID-19 Vaccines.

All incidence rates are annual per 100,000 persons. Accuracy: 8\%; Reporting Sensitivity/Multiplier: 30\%/3.3 (vertigo: 0.6\%/166.9); Overall: 28\% (vertigo: 1,405\%)

\begin{tabular}{|c|c|c|c|c|c|}
\hline $\begin{array}{c}\text { Adverse } \\
\text { event }\end{array}$ & Vaccine & $\begin{array}{c}\text { Cases During } \\
\text { Spike Period / } \\
\text { Total Recipients } \\
\text { over Full } \\
\text { Observation } \\
\text { Period }\end{array}$ & $\begin{array}{c}\text { Incidence over } \\
\text { Spike Period / } \\
\text { General } \\
\text { Population } \\
\text { Incidence }\end{array}$ & $\begin{array}{c}\text { Comparison with } \\
\text { mRNA-1273 } \\
\text { Vaccine: } z \text {-statistic / } \\
\text { p-value (two-tailed) / } \\
\text { Significant at the } \\
\text { 95\% confidence } \\
\text { level? }\end{array}$ & $\begin{array}{c}\text { Comparison with } \\
\text { BNT162b2 Vaccine: z- } \\
\text { statistic / p-value (two- } \\
\text { tailed) / Significant at } \\
\text { the } 95 \% \text { confidence } \\
\text { level? }\end{array}$ \\
\hline \multirow{3}{*}{ 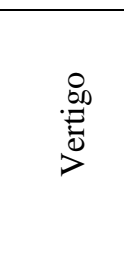 } & mRNA-1273 & $\begin{array}{l}13,434.07 / \\
69,355,687\end{array}$ & $\begin{array}{c}3,534.99 / \\
1,400\end{array}$ & $\mathrm{n} / \mathrm{a}$ & $15.50 /<0.00001 /$ yes \\
\hline & BNT162b2 & $\begin{array}{l}14,684.73 / \\
90,933,285\end{array}$ & $\begin{array}{c}2,947.17 / \\
1,400\end{array}$ & $\mathrm{n} / \mathrm{i}$ & $\mathrm{n} / \mathrm{a}$ \\
\hline & Ad26.COV2.S & $\begin{array}{c}2,571.58 / \\
11,021,766\end{array}$ & $\begin{array}{c}4,258.07 / \\
1,400 \\
\end{array}$ & $8.81 /<0.00001 /$ yes & $17.57 /<0.00001 /$ yes \\
\hline \multirow{3}{*}{$\stackrel{\varrho}{\Xi}$} & mRNA-1273 & $\begin{array}{c}379.94 / \\
69,355,687\end{array}$ & $99.98 / 54$ & $\mathrm{n} / \mathrm{a}$ & $0.0 / 1.0 /$ no \\
\hline & BNT162b2 & $\begin{array}{c}497.53 / \\
90,933,285\end{array}$ & $99.85 / 54$ & $\mathrm{n} / \mathrm{i}$ & $\mathrm{n} / \mathrm{a}$ \\
\hline & Ad26.COV2.S & $\begin{array}{c}94.63 / \\
11,021,766\end{array}$ & $156.70 / 54$ & $3.88 /<0.001 /$ yes & $3.99 /<0.0001 /$ yes \\
\hline \multirow{3}{*}{ 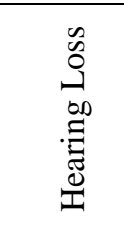 } & mRNA-1273 & $\begin{array}{c}63.28 / \\
69,355,687 \\
\end{array}$ & $33.30 / 27$ & $\mathrm{n} / \mathrm{a}$ & $\mathrm{n} / \mathrm{i}$ \\
\hline & BNT162b2 & $\begin{array}{c}93.23 / \\
90,933,285\end{array}$ & $37.42 / 27$ & $0.64 / 0.52 /$ no & $\mathrm{n} / \mathrm{a}$ \\
\hline & Ad26.COV2.S & $\begin{array}{c}28.00 / \\
11,021,766\end{array}$ & $92.72 / 27$ & $4.56 /<0.00001 /$ yes & $4.21 /<0.0001 /$ yes \\
\hline “ & “ & “ & “ & “ & $\begin{array}{c}\text { Comparison with } \\
\text { Ad26.COV2.S } \\
\text { Vaccine: . . . }\end{array}$ \\
\hline \multirow{3}{*}{ 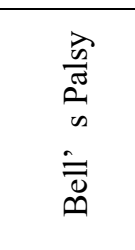 } & mRNA-1273 & $\begin{array}{c}139.15 / \\
69,355,687 \\
\end{array}$ & $36.62 / 23$ & $\mathrm{n} / \mathrm{a}$ & $0.0 / 1.0 /$ no \\
\hline & BNT162b2 & $\begin{array}{c}184.51 / \\
90,933,285\end{array}$ & $37.03 / 23$ & $0.04 / 0.96 /$ no & $0.05 / 0.96 /$ no \\
\hline & Ad26.COV2.S & $\begin{array}{c}21.56 / \\
11,021,766\end{array}$ & $35.70 / 23$ & $\mathrm{n} / \mathrm{i}$ & $\mathrm{n} / \mathrm{a}$ \\
\hline
\end{tabular}


Figure 1: The Early-Onset Spike in VAERS Reports: All Adverse Events Reported to VAERS for All Vaccines, COVID19 and Non-COVID-19, Administered between December 14, 2020 and June 7, 2021.

800,000

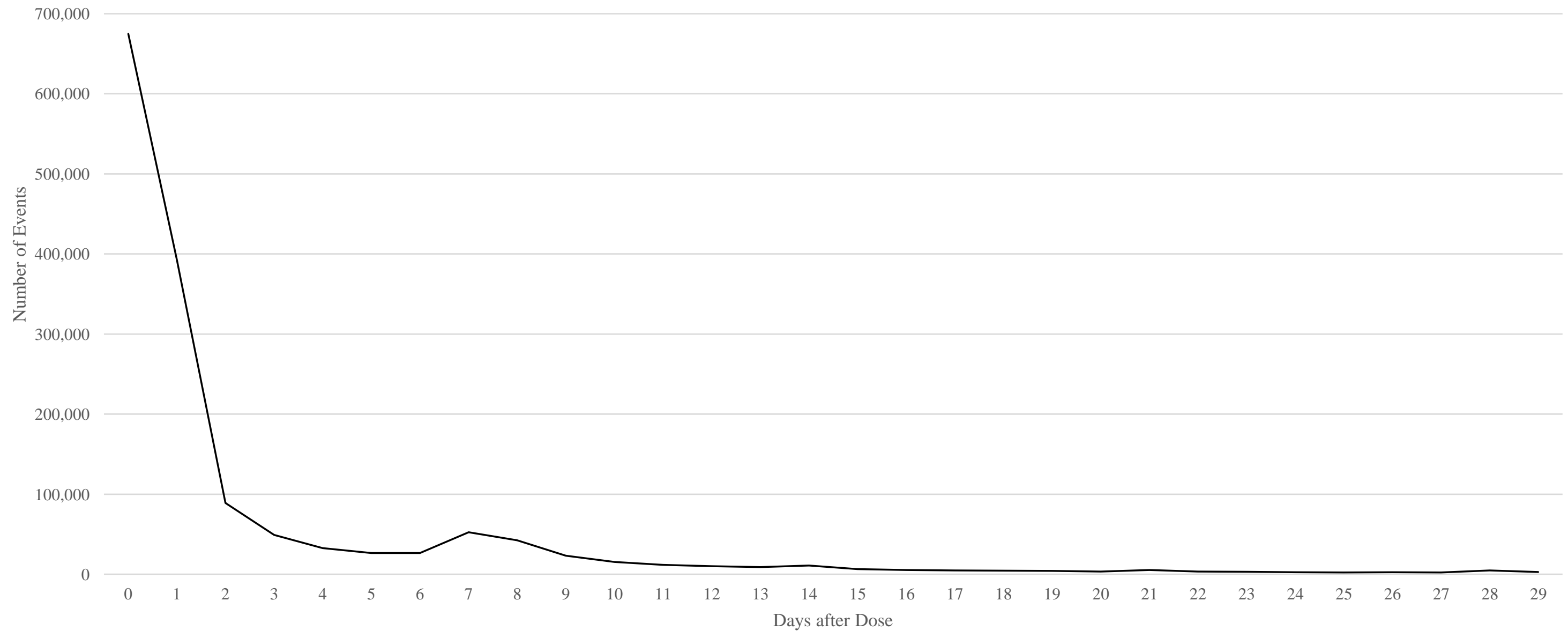


Figure 2: Triangle Venn Diagram Showing the Intersection of the Sets of Reports of Vertigo (V), Tinnitus (T), and Hearing Loss (H) in VAERS data.

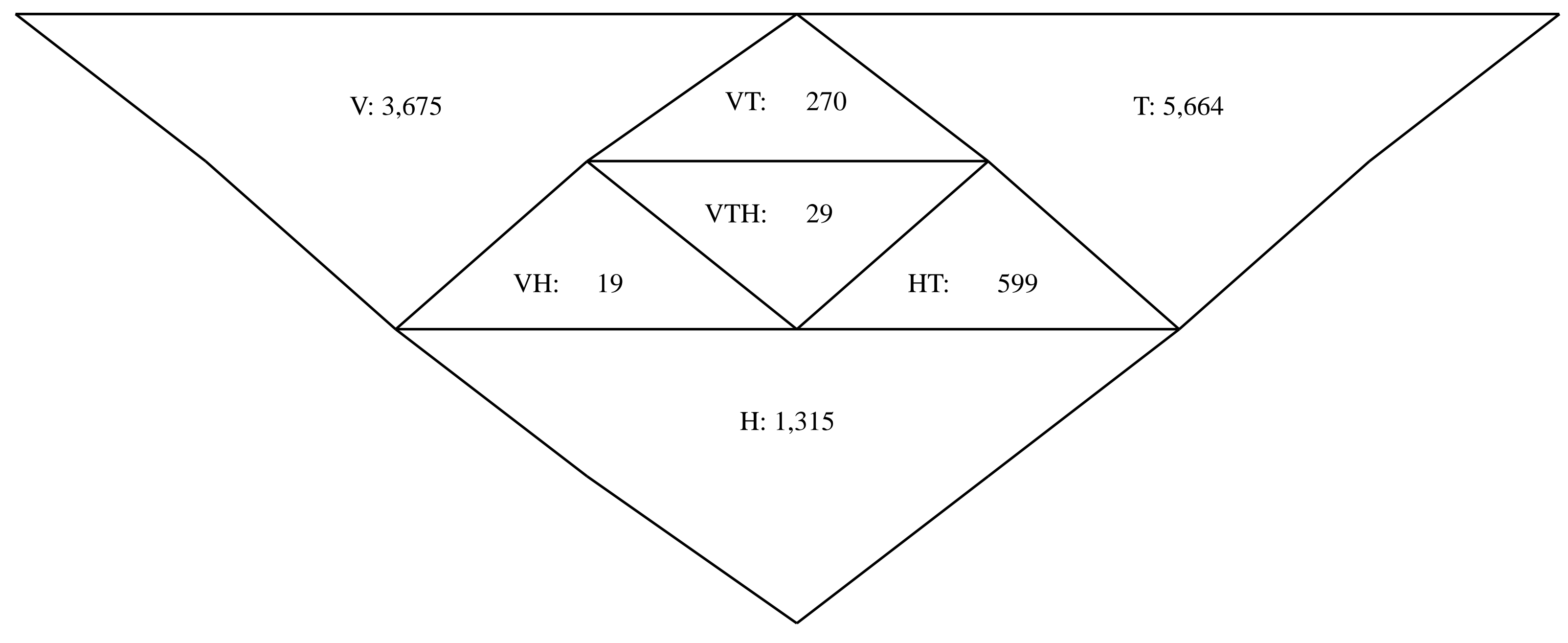


Figure 3:

Spike Periods for Otologic Symptoms: Reports to VAERS of (a) Vertigo, (b) Tinnitus, (c) Hearing Loss, and (d) Bell's Palsy in Relation to the COVID-19 Vaccines for Doses Administered between December 14, 2020 and June 7, 2021, Showing Spike Periods During Which Reported Cases Exceed Expected Cases.

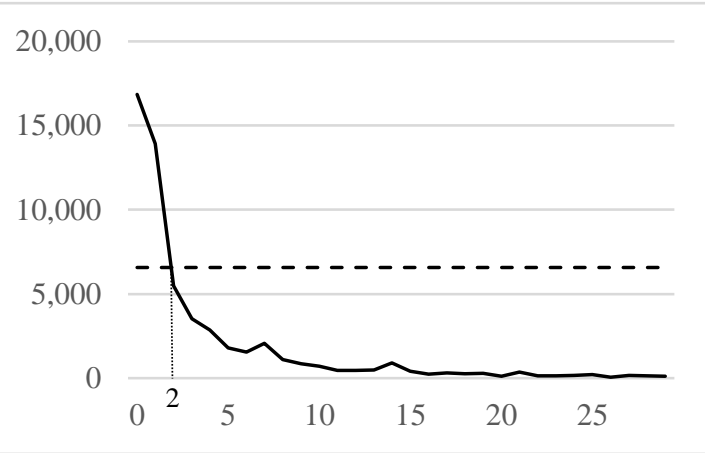

(a)

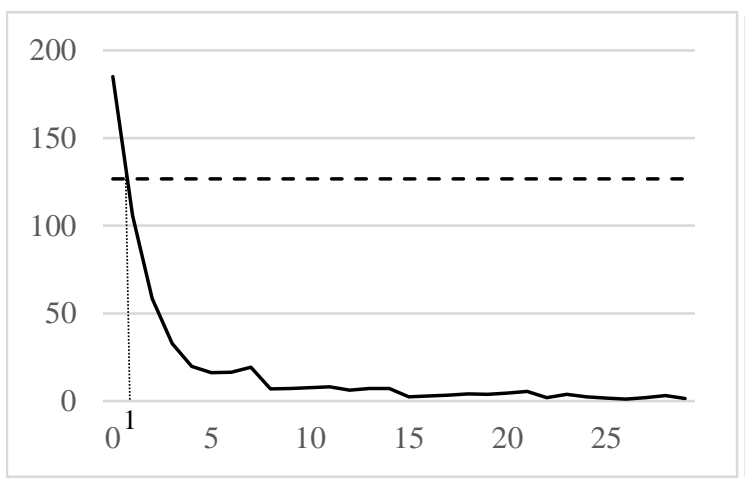

(c)

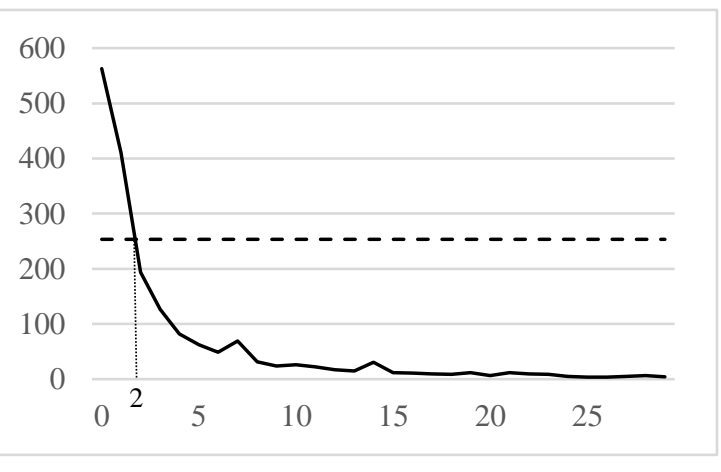

(b)

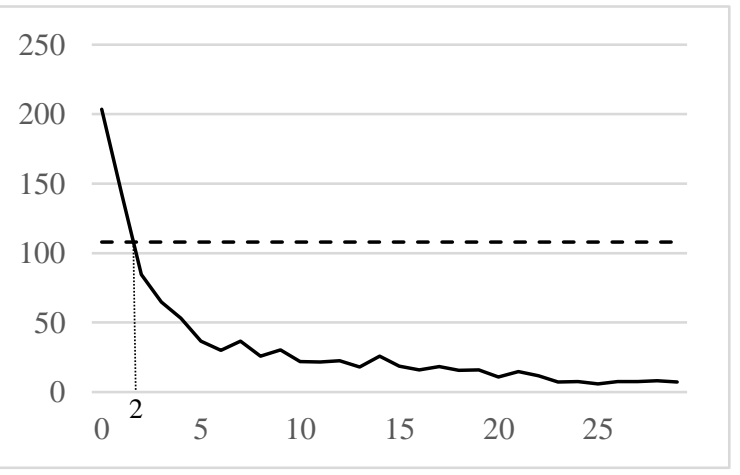

(d)

The solid line shows the number of cases reported and the horizontal dashed line shows the expected number of cases based on the population incidence rate. The vertical dotted line shows the number of days after dose administration at which the spike of reported cases above expected cases ends. The vertical axis is labeled in report numbers and the horizontal access is labeled in the number of days between administration of the dose and symptom onset. An accuracy discount rate of $8 \%$ has been applied to all case counts, an underreporting multiplier of 3.3 has been applied to the tinnitus, hearing loss, and Bell's palsy case counts, and an underreporting multiplier of 166.9 has been applied to the vertigo case counts. 